\title{
Em busca do novo proletariado periférico: trabalhadores dos serviços e a "nova morfologia do trabalho"1
}

Tiago Magaldi2

Resenha do livro:

ANTUNES, Ricardo. O privilégio da servidão: o novo proletariado de serviços na era digital. São Paulo: Boitempo, 2018.

\section{Introduç̃̃o}

Os recentes escritos do sociólogo marxista Ricardo Antunes possuem dois eixos analíticos principais: a crítica severa de teorias que afirmam a mitigação, ou mesmo o fim, do trabalho como elemento central da sociabilidade na sociedade capitalista contemporânea ${ }^{3}$ e a reafirmação da relevância explicativa da teoria do valor-trabalho marxiana para a análise das transformações sociais, sobretudo as relativas à política dos trabalhadores. O privilégio da servidão não foge à regra. Concebido como uma coletânea de artigos publicados no intervalo entre os anos de 2010 e 2018 (apenas dois de seus vinte capítulos são inéditos), em vários deles - como é típico de artigos - o autor indica no início os pressupostos que guiarão a análise, o que pode dar ao leitor a sensação de estar, a cada capítulo, recomeçando a leitura,

\footnotetext{
1 O presente trabalho foi realizado com apoio da Coordenação de Aperfeiçoamento de Pessoal de Nível Superior - Brasil (CAPES).

2 Programa de Pós-Graduação em Sociologia da Universidade Federal de São Carlos (PPGS-UFSCar) - São Carlos - Brasil - tmgranato@gmail.com

3 Da qual o exemplo mais bem acabado é o seu já clássico Adeus ao trabalho? (2015).
} 
sobretudo nas duas primeiras partes. No entanto, mais que um repisar de temas e teses caros ao autor, a obra oferece insights de interesse para o estudioso do trabalho, em especial àquele identificado com a tradição marxista, mas não somente a ele.

O livro possui quatro partes, cada uma composta por vários capítulos. Embora o fio da meada quase se rompa na terceira parte - que enfeixa avaliações de conjuntura quase estritamente políticas que não se conectam diretamente com a apresentação inicial da "nova morfologia do trabalho" -, é possível notar ao fundo o arco geral do argumento do autor, que se estende da explicitação de uma nova composição da "classe-que-vive-do-trabalho" - com o "novo proletariado de serviços" servindo como o seu emblema -, até a inadequação do movimento sindical e do próprio governo produzido pelo "novo sindicalismo" para lidar com os desafios políticos que esta nova composição exige, passando pela "devastação" da regulação trabalhista sob a hegemonia neoliberal das últimas décadas.

\section{Trabalho produtivo, proletarização e a "devastação do trabalho"}

Na primeira parte do livro, o leitor encontra o capítulo que o próprio autor classifica como seu "fio condutor" ("A explosão do novo proletariado de serviços", o segundo), no qual apresenta a principal proposição analítica da obra. Detenhamo-nos aqui, portanto. Neste capítulo, lemos que a partir da década de 1970 o capitalismo mundial, em crise, começa um processo de reestruturação produtiva que continua até os dias de hoje, visando ao aumento tanto da produtividade do trabalho quanto da extração de mais valor, por meio das novas tecnologias informacionais. Desde então, o setor de serviços, sobretudo os digitais, vem ganhando relevância, bem como vem aumentando o contingente de trabalhadores que emprega - embora, frisa sempre o autor, isso não signifique absolutamente o fim do trabalho material, que ganha imensos novos contingentes em países como China e Índia. O autor então se pergunta em que medida seria possível considerar, em termos marxistas, os serviços como produtivos, isto é, como geradores de mais-valor para o capital. Como é frequente na obra de Antunes, a busca do avanço teórico decorre de uma exegese dos escritos marxianos. Voltando ao Livro II e III de O Capital, o autor traz a análise de Marx sobre a indústria dos transportes - um "serviço" - enquanto um processo de produção dentro do processo de circulação. Uma vez tomado o movimento espacial de mercadorias como extensão do próprio processo de produção, fica claro o efeito útil do trabalho de transporte sobre o 
produto, e, portanto, sua participação na adição de valor a ele. Tratar-se-ia de um trabalho que acrescenta mais-valor ao produto, mais-valor este extraído de seus trabalhadores.

O debate sobre trabalho "produtivo" e "improdutivo" na literatura marxista é vasto ${ }^{4}$, e supera os propósitos desta resenha alocar as hipóteses de Antunes em seu quadro. $\mathrm{O}$ importante aqui é destacar que o autor pretende aplicar analogicamente as análises de Marx sobre a indústria de transportes ao setor de serviços na era digital com o propósito explícito de afirmar o caráter produtivo do trabalho imaterial que encontramos neste setor. Por outro lado - segue o autor -, se é manifestação da mesma lógica capitalista já delineada por Marx, o setor de serviços contemporâneo é também diferente: as novas tecnologias da informação e comunicação (“TICs") permitem uma redução sem precedentes do tempo de não trabalho, bem como facilitam uma extrema flexibilização do trabalhador (da qual o melhor exemplo seria "contrato de zero horas" britânico). Trata-se de uma ampliação da extração do mais-valor, que avança sobre o trabalho imaterial e por meio dele. Avança sobre o trabalho imaterial por ter este se tornado produtivo e, portanto, fonte de extração de mais-valor; avança pelo trabalho imaterial porque este, em função da natureza de sua atividade, reduz o tempo de não-trabalho, acelerando o giro do capital e, consequentemente, seu processo de valorização. Assim, contrariamente às teses que defendiam o fim do trabalho na era digital, estaríamos vivenciando um crescimento exponencial de um novo proletariado de serviços, superexplorado enquanto trabalho vivo e precarizado em função da redução do tempo de não-trabalhos.

Essa chave analítica, exposta logo no início do livro, fundamenta o desenvolvimento explicativo dos capítulos diretamente seguintes. A segunda parte do livro apresenta três estudos de caso que ilustram o que Antunes chama de "nova morfologia do trabalho": o setor metalúrgico (trabalhadores de uma unidade da General Motors instalada em São José dos Campos-SP), a agroindústria (trabalhadores canavieiros de uma usina em Cosmópolis, interior de São Paulo) e o setor de serviços de telecomunicação (trabalhadores de telemarketing e call-center de uma grande empresa de Campinas). A análise desses setores nos conduz à conclusão de uma precarização geral do trabalho, que avança sob o signo da terceirização ("a terceirização é o fio condutor da precarização 
do trabalho no Brasil" [2018: 163]), e que tem sua expressão mais dolorosa em um novo mapa de acidentes e doenças profissionais: a exigência de metas que crescem à medida que são cumpridas; a experiência de uma intensa solidão, em meio à frenética concorrência interna promovida pelo próprio capital dentro de suas empresas; o apagar das fronteiras entre tempo de trabalho e tempo de não trabalho em função da flexibilização de horários e das novas tecnologias digitais, o aumento da intensidade do trabalho; e mesmo o aumento dos acidentes de trabalho são as diferentes facetas que compõem o calvário do "novo" trabalhador. Em suma, a atual fase do capitalismo exigiria a "devastação do trabalho", isto é, a suspensão de toda e qualquer proteção legal ao trabalhador, deixando-o "livre" para ser explorado ao limite de suas forças, tal e qual o proletariado descrito classicamente por Marx, à exceção de que o atual estaria sujeito a determinadas tecnologias que acelerariam ainda mais o tempo de trabalho e diminuiriam o tempo livre. Chega-se à "nova morfologia do trabalho", em formação desde a década de 1970, por meio do processo de precarização das relações trabalhistas ("pejotização", contratos intermitentes, remuneração variável, terceirizações) e de precarização do próprio trabalho (aumento da intensidade, redução do tempo livre, aumento de acidentes, adoecimento psíquico). É este vigoroso processo em curso que dá conteúdo à afirmação, em si um tanto prosaica, de que a classe trabalhadora hoje é mais "complexa e fragmentada do que o proletariado industrial do século XIX e do início do XX" (2018: 89).

\section{A "rota surpreendente" gestada pelo "novo sindicalismo" - e seu colapso}

Antunes então se pergunta como os trabalhadores organizados vêm enfrentando tais ataques. Para elaborar a resposta, o livro se torna mais descritivo e menos analítico, deslocando seu eixo temático do mundo do (ambiente de) trabalho para o da política propriamente dita. Sindicatos, centrais, governos e partidos entram em cena. $\mathrm{O}$ autor esboça uma história do "novo sindicalismo" e das oposições sindicais, ambos em suas manifestações estritamente paulistas, e nos conduz da "fase heroica" do movimento que desaguaria na formação da Central Única dos Trabalhadores (CUT), tida como classista e impulsionada por uma postura de confronto, até sua degeneração em um "sindicalismo negocial" na década de 1990, sob a difícil conjuntura do triunfo da hegemonia neoliberal no Brasil e no mundo. A fusão entre neoliberalismo e reestruturação produtiva, ao incentivar a flexibilização, a terceirização e a informalidade teria deixado pouca margem de ação ao sindicalismo classista; a negociação passa a ser a 
tônica da organização sindical. Em função da nova postura, durante a década de 1990 a CUT teria deixado de acentuar o componente de classe em seu movimento, passando gradualmente a uma defesa abstrata da "cidadania".

Se a CUT passou por uma metamorfose para adaptar-se à nova hegemonia neoliberal, a Força Sindical já teria nascido sob o seu signo. Fundada em 1991 e autodeclarada como a central da "modernização" das relações trabalhistas, Antunes é taxativo ao ver nela "a pragmática neoliberal no interior do sindicalismo" (2018: 204). A nova central objetivava uma verdadeira transformação da sociedade brasileira por meio da transformação de sua cultura sindical. Crítica tanto do "radicalismo" cutista quanto do "conformismo" pelego, seu discurso era o de que os trabalhadores não deveriam opor-se à "modernização" capitalista, mas sim participar ativamente dela. Ironicamente, ambas as centrais - adversárias ferozes durante a década de 1990 - uniram forças sob o governo Lula da Silva (2003-2010).

Aqui já entramos no arco descendente do livro, caminhando para seu desfecho. A análise da experiência do Partido dos Trabalhadores (PT), a "rota surpreendente" do "social-liberalismo" - como Antunes caracteriza tanto o período petista quanto o do Labour Party inglês -, é feita sob o signo da "conciliação". Lula, um "gênio político", teria, com o seu partido, conseguido tornar-se um confiável gestor do capitalismo brasileiro, à semelhança de Tony Blair na Inglaterra. Com o apoio das maiores centrais sindicais, favorecendo as classes dominantes, e com uma relação "direta" com as massas mais empobrecidas do país por meio de políticas "puramente assistencialistas" (das quais o Bolsa-Família seria o melhor exemplo), Lula teria encarnado "uma espécie de semi-Bonaparte" (2018: 225) cordial e extremamente hábil no manuseio de sua base social. Mas, ao não enfrentar os pilares estruturais da desigualdade brasileira, seu projeto de conciliação estava com os dias contados. A rebelião da juventude em 2013, já durante o governo de Dilma Rousseff, teria marcado definitivamente o fim do projeto conciliatório petista. Terminava a "era das conciliações" e abria-se a "era das rebeliões".

Por fim - prossegue o autor -, o descontentamento geral, especialmente o dos jovens, por conta das difíceis condições de vida nas metrópoles, da privatização de serviços, sobretudo saúde e educação, da publicização de imensos esquemas de corrupção e da aproximação de um período econômico recessivo; bem como o ódio ao PT cultivado pelas classes médias em função das melhoras pontuais das condições de vida dos mais excluídos e a disposição dos agentes políticos em torpedear o governo petista deixaram claro que a crise brasileira era profunda, atingindo os planos social, político, econômico e institucional. 
Quando a crise econômica finalmente chega ao Brasil, em finais de 2014, as classes dominantes passam a ter de decidir sobre quem recairá seu ônus. A partir de então, um governo de conciliação deixa de ser necessário, e a intenção golpista se torna real, consumando-se com o impeachment de Dilma Rousseff e com a ascensão de Michel Temer à presidência do Brasil. Temer era o representante da contrarrevolução brasileira e se propôs a terminar o trabalho neoliberal da década de 1990 de varrer definitivamente a proteção ao trabalho.

O título da última parte do livro é autoexplicativo ("Há alguma luz no fim do túnel?"), bem como os dos dois capítulos que a compõem ("Há futuro para os sindicatos?" e "Há futuro para o socialismo?"). Trata-se da parte explicitamente normativa do livro, no sentido prescritivo. Se o autor argumenta que temos hoje uma "nova morfologia do trabalho", decorrente de décadas de hegemonia neoliberal, é natural que vislumbre a necessidade de um novo desenho das formas de representação do trabalho. Para tanto, apresenta uma verdadeira agenda para a revitalização dos organismos sindicais de classe. Correndo o risco de simplificação, podemos dizer que toda ela se resume em uma defesa da ampliação e do fortalecimento de sua representação. Para Antunes, os sindicatos são verticalizados, corporativos, indiferentes às questões de gênero, de raça e étnica; são burocratizados, conciliatórios e pouco internacionalizados, bem como reféns de estratégias meramente parlamentares. Em suma, os sindicatos devem ampliar a sua atuação para os setores desprotegidos - terceirizados, precarizados, informais e mesmo desempregados -, aumentando a sua cobertura, bem como ampliar suas táticas, deixando para trás aquelas apenas viáveis sob contextos históricos de conciliação de classe, hoje - segundo o autor - inúteis. Agindo assim os sindicatos estariam recuperando a dimensão classista da luta política, e trazendo para si os novos trabalhadores. A defesa do socialismo segue o mesmo apelo. $\mathrm{O}$ autor critica o privilégio das lutas parlamentares e reforça a necessidade de organizar a luta do trabalho de forma extraparlamentar para conseguir superar o tripé "capital, trabalho e Estado" que conformaria o capitalismo. Para tanto, é fundamental recuperar o sentido de pertencimento de classe, bem como formas de atuação autônoma frente ao capital, pois o processo de emancipação dar-se-á "simultaneamente do trabalho, no trabalho e pelo trabalho" (2018: 304, grifos do autor). Apenas assim seria possível superar o capitalismo e construir um "novo modo de vida", baseado na rejeição do trabalho assalariado, fetichizado e estranhado, pois "uma vida desprovida de sentido no trabalho é incompativel com uma vida cheia de sentido fora do trabalho" (2018: 305, grifo do autor). 


\section{Uma crítica}

Exposta a linha central do argumento, gostaríamos de examinar mais de perto o método sobre o qual o livro se apoia. Ele é fortemente dedutivo, muito afeito a recorrer a "exemplos emblemáticos" para ilustrar seu argumento teórico. Embora recorra, em apenas um dos capítulos de todo o livro, a estudos de caso sobre categorias específicas, é comum que faça uma afirmação teórica e, em seguida, apresente exemplos para ilustrar - a palavra é exatamente essa - o argumento. A meu juízo, o que este procedimento ganha em abrangência explicativa perde em densidade. A experiência de operários chineses do setor de montagem de celulares, de trabalhadores digitais sem teto japoneses, motoristas de Uber norte-americanos ou trabalhadores intermitentes italianos pode mesmo ser diretamente reduzida a um denominador comum, sem maior densidade contextual? As causas que determinam concretamente o suicídio coletivo em empresas chinesas seriam as mesmas que levam à greve o trabalhador italiano? Não se questiona aqui a explicitação de linhas de força transnacionais do capitalismo contemporâneo, nem mesmo seu caráter precarizador, onipresentes na literatura sobre o trabalho, mas a grande perda empírica que uma dedução de longuíssimo alcance - no limite, de alcance planetário - exige. Detendo-nos no denominador comum desses fenômenos corremos o risco de perder aquilo que os diferencia concretamente: qual flexibilidade? Que tipo de gestão por metas? Como ocorre concretamente a remuneração variável? Terceirização de quem e em quais setores? Quais as especificidades nacionais? Em suma: a qual contexto concreto ligam-se as diferentes iniciativas precarizadoras dos diferentes capitais particulares e como elas interagem com os diferentes contextos para os quais são designadas? Atribuir um protagonismo esmagador à "lógica do capital na era digital" reduz a muito pouco os agentes que concretamente a tornam realidade; em especial, ignoram os complexos processos por meio dos quais os próprios trabalhadores - organizados ou não - pensam e agem criticamente sobre tais iniciativas. Não por acaso, o capítulo que trata sobre a "subjetividade operária" é, relativamente à caracterização do trabalho nos serviços, pouco desenvolvido.

Talvez uma comparação ajude a esclarecer o ponto. Ao descrever o toyotismo (ou, como prefere chamar, o "ohnismo"), Benjamin Coriat (1994) não apenas considera a "lógica" que emana da produção intelectual de seu fundador, Ohno, mas ressalta particularmente as condições concretas bastante específicas (mercado interno reduzido, restrições financeiras e sindicato "de empresa") que permitiram o surgimento do toyotismo como padrão de produção da 
indústria automotiva japonesa. Ele não surge como expressão de uma "lógica do capital" que paira acima das condições concretas; ele não ilustra a "lógica do capital" de sua época, ele era a própria "lógica" em ato, resultado necessário de determinadas interações. Isto porque foram necessidades e interesses específicos, particulares, que fizeram surgir o toyotismo e, na medida em que possuía afinidade com outros interesses e necessidades particulares alheios ao contexto no qual surgiu, universalizou-se enquanto "lógica". Na presente obra a complexa passagem do particular ao universal parece ausente, ou, ao menos, em franco desequilíbrio em relação ao movimento oposto. Por outro lado, é legítimo perguntar-se se seria possível, dado o alcance explicativo intentado pelo autor - expor um movimento de cobertura planetária -, proceder de maneira diferente.

\section{Conclusão}

Evidentemente, a crítica apresentada não pretende minimizar a importância das reflexões expostas na obra; tão somente aponta para a necessidade - nunca plenamente satisfeita no trabalho científico - de dar "carne e osso" àquilo que chegamos por meio da teoria, por mais cristalina que esta seja apresentada. A analogia do setor de transportes com o de serviços digitais é perspicaz e abre novas perspectivas teóricas e empíricas; a denúncia da "devastação do trabalho", embora hiperbólica nos termos utilizados - o que revela claramente a posição normativa do autor, mas tende a esconder a dos atores sobre os quais a "devastação" se abate -, exibe fartos indícios de realidade; por fim, a reconstrução da trajetória de contínuo solapamento da proteção ao trabalho, inclusive por intermédio de centrais sindicais e mesmo durante os governos petistas, embora polêmica - ou justamente por isso -, oferece uma rica avaliação sobre os caminhos e descaminhos pelos quais os trabalhadores brasileiros e seus representantes passaram nas últimas três décadas. Esses pontos, destacados como principais dentre muitos outros que nos são apresentados na obra, fazem do livro um trabalho relevante para pensar um Brasil que se reconfigura, e cujo horizonte parece ser sombrio para os trabalhadores.

\section{Referências}

ANTUNES, Ricardo. Adeus ao trabalho? Ensaio sobre as metamorfoses e a centralidade do mundo do trabalho. São Paulo, Cortez, 2015 (288).

O privilégio da servidão: o novo proletariado de serviços na era digital. São Paulo, Boitempo, 2018 (328). 
CORIAT, Benjamin. Pensar pelo avesso: o modelo japonês de trabalho e organização. Rio de Janeiro, Revan, UFRJ, 1994.

DIAS, Cristina Maria Nogueira Parahyba. Trabalho produtivo e trabalho improdutivo: de Marx à polêmica marxista (Napoleoni, Rubin e Mandel). Tese de doutorado, Serviço Social, Universidade Federal do Rio de Janeiro, 2006.

Recebido em: 02/04/2019

Aprovado em: 10/05/2019

\section{Como citar esta resenha:}

MAGALDI, Tiago. Em busca do novo proletariado periférico: trabalhadores dos serviços e a "nova morfologia do trabalho". Contemporânea - Revista de Sociologia da UFSCar, v. 9, n. 2, maio - agosto. 2019, pp. 683-691. 